\title{
Management of complications from brain metastasis treatment: a narrative review
}

\author{
Kevin Diao', Alan J. Sosa ${ }^{1}$, Gabriel Zada ${ }^{2}$, Seema Nagpal ${ }^{3}$, Eric L. Chang ${ }^{1,4}$ \\ ${ }^{1}$ Department of Radiation Oncology, The University of Texas MD Anderson Cancer Center, Houston, TX, USA; ${ }^{2}$ Department of Neurological \\ Surgery, University of Southern California Keck School of Medicine, Los Angeles, CA, USA; ${ }^{3}$ Department of Neurology, Stanford University, \\ Stanford, CA, USA; ${ }^{4}$ Department of Radiation Oncology, University of Southern California Keck School of Medicine, Los Angeles, CA, USA \\ Contributions: (I) Conception and design: All authors; (II) Administrative support: EL Chang; (III) Provision of study materials or patients: K Diao, \\ EL Chang; (IV) Collection and assembly of data: K Diao, AJ Sosa; (V) Data analysis and interpretation: All authors; (VI) Manuscript writing: All \\ authors; (VII) Final approval of manuscript: All authors. \\ Correspondence to: Kevin Diao, MD. FCT6.5075, T. Boone Pickens Academic Tower, 1400 Pressler St., Houston, TX 77030, USA. \\ Email: kdiao@mdanderson.org.
}

Objective: To describe the range of potential side effects associated with modern brain metastasis treatment and provide evidenced-based guidance on the effective management of these side effects.

Background: Brain metastases are the most commonly diagnosed malignant intracranial tumor and have historically been associated with very poor prognosis. The standard treatment for brain metastases until the 1990s was whole-brain radiation therapy (WBRT) alone. Since then, however, numerous advances have established the role of neurosurgical resection, stereotactic radiosurgery (SRS), targeted systemic therapy, and immunotherapy in the multidisciplinary management of brain metastases and led to improvements in intracranial control, survival, and neurocognitive preservation among patients with brain metastases. As a result, however, brain metastasis treatment is associated with a wider range of potential side effects than ever before, and clinicians are tasked with the challenge of effectively managing these side effects without compromising cancer outcomes.

Methods: We performed a narrative review of peer-reviewed articles related to the management of side effects from multidisciplinary brain metastasis treatment and synthesized the data in the context of our clinical experience and practice.

Conclusions: In this review, we summarize the major complications from intracranial radiotherapy, neurosurgical resection, and brain metastasis directed systemic therapy with corresponding evidenced-based, modern management principles to guide the practicing oncologist.

Keywords: Brain metastasis; treatment; complication; toxicity; management

Submitted Aug 09, 2021. Accepted for publication Sep 27, 2021.

doi: $10.21037 /$ cco-21-90

View this article at: https://dx.doi.org/10.21037/cco-21-90

\section{Introduction}

Brain metastases represent the most commonly diagnosed malignant intracranial tumor (1), occurring in up to half of all patients with cancer (2). The incidence of brain metastases is increasing because of improved imaging modalities allowing for more accurate detection of brain metastases, better awareness among oncologists leading to more frequent surveillance imaging, and improved cancer therapies which have led to longer periods of time during which brain metastases may develop $(3,4)$. In addition, improved systemic therapies used in the metastatic setting may not achieve the same effects in the central nervous system (CNS) due to the blood-brain barrier (5).

Historically, brain metastases were near-uniformly associated with poor outcomes. The standard treatment for brain metastases until the 1990s was whole-brain radiation 
therapy (WBRT) alone, which was associated with a median survival of 3-6 months (6). Since then, however, a plethora of research and treatment advances has fundamentally transformed the landscape of brain metastasis management. Level I data showed the addition of surgical resection to WBRT for patients with a single brain metastasis improved overall survival (OS), and the addition of WBRT to surgical resection improved local and distant brain control and neurologic death, establishing the role of selective surgical resection in patients with brain metastases (6,7). Multiple trials compared stereotactic radiosurgery (SRS) versus SRS + WBRT for patients with limited brain metastases and found similar OS but better neurocognitive preservation and health-related quality-of-life (QOL) with SRS alone (8-11). Two trials examined the role of post-operative SRS which found improved local control (LC) compared to observation (12) and better QOL compared to WBRT (13).

More recently, targeted systemic agents and immunotherapy have demonstrated clinically meaningful intracranial activity in patients with certain cancer histologies (2,14-17). In some carefully selected patients with brain metastases, systemic agents can be used as a frontline treatment option. Certain novel immunotherapy agents are postulated to have a synergistic effect with radiotherapy and may offer an intracranial control and OS benefit when combined with SRS $(18,19)$.

As patients survive longer following brain metastasis treatment, however, late neurologic complications from brain metastasis directed therapy are also becoming more likely. Furthermore, due to the number of treatment options now available, clinicians are faced with a wide range of potential treatment-related complications in patients with brain metastases from radiotherapy, surgical resection, and systemic therapy and managing these complications appropriately is increasingly complex. In this review, we aim to describe the major potential complications from brain metastasis treatment with an emphasis on modern, evidenced-based clinical management. We present the following article in accordance with the Narrative Review reporting checklist (available at https://cco.amegroups.com/ article/view/10.21037/cco-21-90/rc).

\section{Complications after intracranial radiotherapy}

The definition of CNS toxicity is variably categorized into acute versus late or acute, early-delayed, and late by different sources (20). The Radiation Therapy Oncology Group (RTOG) defines acute CNS toxicities as those occurring within 90 days of radiation treatment and late CNS toxicities as those occurring after 90 days of treatment (21). From a radiobiological standpoint, distinct histopathological types of injury have been described in the acute, early-delayed, and late timepoints. Acute injury has been described as occurring within either 30 days after treatment, early-delayed injury as occurring 30 days to 6 months after treatment, and late injury as occurring greater than 6 months after treatment $(22,23)$. For the purposes of this practical review, we will follow the RTOG definition of acute and late CNS toxicity.

\section{Acute complications}

\section{Fatigue}

Fatigue is common during and after cranial radiotherapy (Table 1). In patients receiving WBRT, up to $95 \%$ of all patients experience excess fatigue and prospective studies have identified deterioration in validated fatigue scores from baseline to 1 month after WBRT $(24,25)$. However, fatigue is common with brain metastases in general and may be difficult to separate from treatment-related fatigue, as demonstrated in the QUARTZ trial, where $40 \%$ of patients who received WBRT vs. $44 \%$ of patients who received supportive care only reported tiredness (26). On the other hand, fatigue may be less common following SRS, reported by only $28 \%$ of patients compared to $95 \%$ of patients who underwent WBRT in one series (24).

The primary management of acute fatigue in patients undergoing brain radiotherapy is supportive care, including appropriate steroid taper, advising patients to take steroids earlier in the day (second dose no later than mid-afternoon) to avoid sleep disturbance, and other good sleep hygiene measures. Numerous studies demonstrate that aerobic and resistance exercise can mitigate cancer-related fatigue to an extent, and despite lack of data specifically in patients undergoing brain radiotherapy, we agree with the American Society of Clinical Oncology (ASCO) recommendations for 150 minutes of moderate aerobic exercise (including fast walking, cycling, or swimming) per week with an additional $2-3$ sessions of resistance exercise (such as weightlifting), unless contraindicated for medical reasons (27-31). Psychostimulants are not indicated for acute fatigue.

\section{Alopecia and dermatitis}

Complete alopecia is common following WBRT and may be acute or chronic, typically beginning during WBRT or up to 
Table 1 Radiotherapy complications of brain metastasis treatment and management options

\begin{tabular}{|c|c|}
\hline Complication & Management options \\
\hline Fatigue & $\begin{array}{l}\text { Appropriate steroid taper and administration instructions (second dose no later than } \\
\text { mid-afternoon) } \\
* \quad \text { Sleep hygiene counseling } \\
* \quad \text { Moderate aerobic/resistance exercise }\end{array}$ \\
\hline Alopecia & $\begin{array}{l}\text { * Scalp-sparing radiation techniques } \\
* \quad \text { Topical minoxidil } 5 \% \text { BID } \\
\text { Referral for hair prosthesis }\end{array}$ \\
\hline Nausea/vomiting & $\begin{array}{l}\text { Without other signs/symptoms of elevated ICP } \\
\text { - Ondansetron } 8 \mathrm{mg} \text { q8 hours PRN } \\
\text { With other signs/symptoms of elevated ICP } \\
\text { - Systemic corticosteroids with dosing based on severity of presentation } \\
\text { develops immediately after RT treatment, ondansetron can be given prophylactically } 1-2 \\
\text { hours prior to subsequent treatments }\end{array}$ \\
\hline Neurocognitive preservation & $\begin{array}{l}\text { - Memantine during and for } 6 \text { months after WBRT (maintenance dose of } 10 \text { mg PO BID) } \\
\text { SRS with omission of WBRT } \\
\text { HA-IMRT techniques }\end{array}$ \\
\hline
\end{tabular}

Table 1 (continued) 
Table 1 (continued)

\begin{tabular}{ll}
\hline Complication & Management options \\
\hline Neurocognitive decline & Psychostimulants (including methylphenidate 10 mg BID, modafinil 200 mg QD) for \\
& chronic cancer-related fatigue \\
& (maintenance dose of $10 \mathrm{mg}$ QD) \\
Optic neuropathy & In absence of other effective treatment options, consider HBOT ideally initiated within \\
& 72 hours of symptom onset or IV bevacizumab \pm dexamethasone (dosing varies) \\
& Insufficient evidence to recommend corticosteroids, therapeutic anticoagulation, or ACE \\
& inhibitor therapy \\
Neuroendocrine dysfunction & Close clinical and imaging follow up of contralateral optic apparatus \\
& WBRT
\end{tabular}

BID, twice daily; OTC, over-the-counter; PRN, as needed; IV, intravenous; ICP, intracranial pressure; RT, radiotherapy; QD, once daily; $\mathrm{MRI}$, magnetic resonance imaging; PET, positron emission tomography; PPI, proton pump inhibitor; LITT, laser interstitial thermal therapy; HBOT, hyperbaric oxygen therapy; WBRT, whole brain radiation therapy; SRS, stereotactic radiosurgery; HA-IMRT, Hippocampal avoidance intensity-modulated radiation therapy; ACE, angiotensin converting enzyme.

1-2 weeks afterwards. Risk factors for alopecia include older age, radiation dose, volume, and receipt of chemotherapy. In most patients, hair regrowth occurs within 2-4 months after completion of radiation (32). However, in others, chronic alopecia (incomplete hair regrowth $>6$ months after treatment) may occur. Only patients who experience acute alopecia can develop chronic radiation-induced alopecia (33). In our experience, alopecia is uncommon following SRS, although patchy alopecia is possible with higher doses targeted to peripheral lesions (34).

In patients experiencing chronic radiation alopecia, one study found that topical minoxidil 5\% BID improved hair regrowth in $82 \%$ of patients and given its favorable safety profile, is a reasonable option for interested patients (35). Patients with significant chronic alopecia can also be referred for hair prosthesis. Scalp-sparing radiation delivery techniques utilizing intensity-modulated radiation therapy (IMRT) have been developed which appear to both reduce the severity of acute alopecia and significantly reduce the likelihood of chronic alopecia $(33,36,37)$. It should be noted that despite a reduction in scalp radiation dose with IMRT, most patients will still experience acute alopecia with $>50 \%$ hair loss and this technique should therefore be reserved for patients with an expected survival of $>4-6$ months or for those receiving IMRT for other indications (i.e., hippocampal avoidance).

Radiation dermatitis is highly associated with total radiation dose to the skin. Therefore, while erythema and dry desquamation of the scalp are possible with the range of radiation doses typically used for WBRT (20-37.5 Gy), moist desquamation is unlikely to occur (38). The management of radiation dermatitis of the scalp following cranial radiation is similar to other areas of the body. Patients should be counseled to use sunscreen, avoid sun exposure, and keep the area clean and dry. We typically use a gentle hydrophilic moisturizer (i.e., Aquaphor, Beiersdorf Inc., Wilton, CT, USA; Lubriderm, Johnson \& Johnson, New Brunswick, NJ, USA) for grade 1 dermatitis and topical silver sulfadiazine with or without foam absorbent dressings (i.e., Mepilex, Mölnlycke, Gothenburg, Sweden) for grade 2 dermatitis with moist desquamation. Topical corticosteroids, such as hydrocortisone $1 \%$ applied once to twice daily, can be used to reduce irritation and itching.

\section{Headaches, vasogenic edema and nausea}

Headaches are a common complaint during and after intracranial radiation therapy, including both WBRT and SRS. The pathogenesis is thought to be due to transiently increased vasogenic edema from an inflammatory response to tumor. In general, if headaches are mild, transient, and not associated with any new or progressive neurologic deficits, they can be managed conservatively with over-thecounter (OTC) analgesics such as acetaminophen.

On the other hand, more severe, persistent headaches and those associated with nausea, vomiting, and new or progressive neurologic deficits should prompt concern for vasogenic edema. Edema leading to increased intracranial 
pressure (ICP) can be a medical emergency and all patients should be evaluated for signs of elevated ICP and impending herniation, including but not limited to lethargy, nausea/vomiting, severe headache, focal neurologic deficits, cranial nerve palsies, papilledema, and respiratory depression. In the outpatient setting, the mainstay of treatment for vasogenic edema are systemic corticosteroids such as dexamethasone.

The optimal starting dose of dexamethasone depends on the severity of symptoms and underlying vasogenic edema $(39,40)$. In the emergency setting, a loading dose of $10 \mathrm{mg}$ IV followed by $4 \mathrm{mg}$ every 6 hours is commonly used. However, in the outpatient setting, a reasonable starting dose of dexamethasone is 2 to $4 \mathrm{mg}$ PO BID. Clinical improvement typically occurs within 1-3 days, although improvement in vasogenic edema on imaging may lag by 1-2 weeks (41-43). The optimal timing for steroid taper is variable and depends on the status of the underlying condition but should be considered after 7 days of therapy and performed slowly over the course of several weeks. For patients undergoing radiotherapy, we typically continue steroids at least until the end of treatment. Reductions in dose of $50 \%$ should occur no more frequently than every 3-4 days (40). Patients should be instructed to return to their previous dose if they experience rebound symptoms such as worsening headache or recurrent neurologic deficits.

In patients presenting with nausea temporally related to radiation therapy without other signs or symptoms, treatment with a 5-HT3 antagonist such as ondansetron, prescribed $8 \mathrm{mg}$ every 8 hours as needed is reasonable. Cranial radiation is categorized as "low risk" for radiotherapy-induced nausea and vomiting and routine anti-emetic prophylaxis should be avoided (44-46). If other signs or symptoms are present that may be explained by underlying vasogenic edema, corticosteroids with or without a 5-HT3 antagonist should be used as a first-line option.

\section{Pseudoprogression}

Pseudoprogression describes an imaging finding on magnetic resonance imaging (MRI) which cannot reliably be differentiated from tumor progression on conventional MRI, typically characterized by increasing size, T1-weighted contrast enhancement, and peritumoral vasogenic edema of a treated tumor (47). There may be overlap between pseudoprogression and radiation necrosis, which is a pathologic diagnosis, but the two are distinct entities despite sometimes being used interchangeably in medical literature (48). Pseudoprogression is a radiation dose-dependent phenomenon, common following SRS but rare with WBRT alone, and owing to heterogeneous cohorts and definitions, has a reported incidence ranging from 9-31\% (49). Typically, pseudoprogression occurs within 3 months of radiation treatment whereas radiation necrosis can occur months to years afterwards. Numerous studies have found MRI perfusion imaging to be helpful in differentiating pseudoprogression from tumor recurrence (50-52). By definition, most cases of pseudoprogression resolve spontaneously over $2-3$ months and if suspected, can be closely monitored with short interval follow-up MRI. Symptoms from increased vasogenic edema can be managed with steroid therapy as previously described. Progression of imaging changes on subsequent imaging should prompt evaluation for radiation necrosis and/or tumor recurrence.

\section{Late complications}

\section{Radiation necrosis}

Radiation necrosis refers to necrosis of normal brain tissue secondary to radiation treatment. About $80 \%$ of cases occur within 3 years after radiation treatment but in rare cases have been reported up to a decade afterwards $(53,54)$. The clinical presentation of radiation necrosis is variable and depends on the anatomic location affected. In general, radiation necrosis can be asymptomatic, cause global symptoms such as headache, nausea, or vomiting from increased ICP, seizures or focal neurologic deficits that localize to the region of radiation necrosis (54). In most cases, tissue is not obtained and therefore imaging and clinical correlates are used to inform diagnosis. The incidence of symptomatic radiation necrosis following SRS ranges from $4-20 \%$ and is commonly estimated at $10 \%$ overall (55-58). Conversely, the risk of radiation necrosis is minimal $(<1 \%)$ following WBRT alone and standard dosing regimens.

The imaging diagnosis of radiation necrosis is challenging, and biopsy or resection is required for definitive diagnosis. Some authors advocate for the use of terms such as adverse radiation effect (ARE) and treatmentrelated imaging changes (TRIC) as broader terms to capture both reversible and irreversible radiation changes $(19,57)$. Advanced imaging techniques, including perfusion MRI, diffusion-weighted MRI, MRI spectroscopy, and positron emission tomography (PET) can be useful as diagnostic 
adjuncts (59-65). The objectives in the management of radiation necrosis are to palliate symptoms and prevent progressive neurologic deficits. In asymptomatic patients after initial diagnosis of radiation necrosis, close observation with a repeat MRI in 6-8 weeks followed by spacing to every 2-3 months after lesion stability or regression is reasonable as there is no evidence that treatment at this stage will alter disease course. In many patients, the imaging changes will stabilize and improve over the course of weeks to months.

In patients with symptomatic radiation necrosis, systemic corticosteroids such as dexamethasone are the first-line treatment. For patients with mild to moderate symptoms, a starting dose of 2 to $4 \mathrm{mg}$ dexamethasone PO BID is reasonable $(39,40)$. Patients with severe symptoms should be considered for emergent evaluation and potential inpatient management. Symptom improvement occurs rapidly after initiation of steroids but imaging changes, such as improvement in perilesional vasogenic edema, can lag for several weeks. As such, we typically wait at least 4 weeks prior to obtaining repeat imaging. Steroid dose should be maintained for at least 1-2 weeks, and then gradually tapered afterwards over the course of several weeks. Most patients will not require any additional therapy, but for those with either progressive symptoms or inability to tolerate a steroid taper, more aggressive treatments may be considered.

Bevacizumab is a monoclonal antibody that inhibits vascular endothelial growth factor (VEGF). It has been studied for treatment of radiation necrosis in two randomized controlled trials $(66,67)$. In both trials, high rates of radiographic response $(100 \%$ and $66 \%)$ and neurologic symptom improvement (100\% and $62 \%)$ were observed, which were significantly better than with corticosteroid therapy alone. A dose of either $7.5 \mathrm{mg} / \mathrm{kg}$ every 3 weeks or $5 \mathrm{mg} / \mathrm{kg}$ every 2 weeks for up to 4 cycles, lower than those typically used in anti-cancer regimens, can be used. Imaging response can be detected on MRI as early as after 2 cycles. Follow-up MRI can be obtained 8-12 weeks after initiation of therapy and steroid taper can begin around 72 hours after cycle \#1. Retreatment with bevacizumab is feasible and appears efficacious but is not well-studied. Rates of serious adverse events with bevacizumab were low but included pulmonary embolism, sagittal sinus thrombus, and ischemic stroke. The studies excluded patients with active or high risk of bleeding, recent intracranial hemorrhage or major surgery/trauma, significant cardiovascular disease, abdominal fistula or perforation, or poorly controlled hypertension.

Surgical resection may be necessary for cases of refractory radiation necrosis with significant symptoms, contraindication to medical therapy, or uncertainty as to whether a lesion represents radiation necrosis or tumor recurrence. Surgery can offer rapid decompression leading to reduced steroid requirement but is also associated with significant morbidity as represented by one contemporary series where overall morbidity from surgery was $54 \%$ (68). The authors advocated for the use of surgery for radiation necrosis only in cases where all medical therapy had failed. In recent years, laser interstitial thermal therapy (LITT) has also been used successfully to manage refractory radiation necrosis, and offers a minimally invasive alternative guided by MRI. Retrospective data suggests local outcomes comparable to craniotomy albeit with inferior symptom relief (69).

Hyperbaric oxygen therapy (HBOT) has only been studied in small, retrospective series (70-72). In one cohort of 10 patients who underwent HBOT, all either had stabilization of improvement of symptoms and/or imaging findings without severe toxicities (70). Patients were treated at 2.0-2.4 atmospheres for 20-30 sessions lasting 90-120 minutes each. HBOT should not be used in patients with pneumothorax or at high risk for pneumothorax (i.e., chronic obstructive pulmonary disease, lung blebs/bullae, recent thoracic surgery). Its adoption has been limited due to the need for expensive, specialized equipment and the significant time commitment. Anticoagulants such as warfarin and heparin have also been studied in small retrospective series $(73,74)$. The larger included 8 patients with radiation necrosis, of whom 5 symptomatically improved after anticoagulation for a total of 3-6 months (73). One small, retrospective study of 8 patients with radiation necrosis found improvement in edema volume after treatment with vitamin $\mathrm{E}$ and pentoxifylline (75). Overall, the evidence to support HBOT, anticoagulation, and antioxidant therapy for radiation necrosis is weak and these therapies cannot be recommended for routine use.

\section{Neurocognitive decline}

Neurocognitive decline is common in patients with brain metastases, both due to tumor progression as well as from brain metastasis therapy. As many as $90 \%$ of patients with brain metastases will have one or more impaired neurocognitive functions at baseline (76). The management of neurocognitive decline has primarily been directed at 
prevention rather than treatment. The use of fraction sizes $>3$ Gy with WBRT appeared to lead to higher risk for developing severe dementia (77). Two randomized controlled trials have found better neurocognitive preservation with SRS alone compared to SRS with WBRT with similar OS in patients with limited (1-3) brain metastases $(8,9)$. Later reports have validated the use of SRS alone in patients with up to 15 brain metastases $(78,79)$.

Hippocampal avoidance IMRT (HA-IMRT) has also been demonstrated to have better neurocognitive preservation in a randomized phase III trial, although patients with leptomeningeal disease or metastases within $5 \mathrm{~mm}$ of either hippocampus were excluded (80). Due to the time and resource-intensive nature of the treatments, both SRS and HA-IMRT are best suited for patients who are either asymptomatic or only mildly symptomatic from brain metastases and with good performance status. Another scenario where HA-IMRT may be ideal is for prophylactic cranial irradiation (PCI) in small cell lung cancer (SCLC). Two recent randomized trials of HA-IMRT for PCI in SCLC with a dose of 25 Gy in 10 fractions found divergent results with one study finding improved cognitive preservation based on delayed free recall (81), and the other finding no improvement in cognitive preservation based on verbal learning compared to standard WBRT (82). As there was no difference in brain failure, HA-IMRT should be considered for this group of favorable patients without clinically apparent brain metastases.

The use of the N-methyl-D-aspartate (NMDA) receptor antagonist memantine during and for 6 months after WBRT improved preservation of cognitive function, executive function, processing speed, and delayed recognition although its primary endpoint of delayed recall did not reach statistical significance (83). Memantine was started at $5 \mathrm{mg}$ AM for week 1, $5 \mathrm{mg}$ BID for week 2, $10 \mathrm{mg}$ AM and $5 \mathrm{mg}$ PM for week 3, and $10 \mathrm{mg}$ BID for week 4 and maintenance. Due to its favorable side effect profile, memantine should be initiated in most patients receiving WBRT. A randomized trial failed to show benefit of prophylactic methylphenidate on fatigue scores in patients undergoing radiotherapy for primary or metastatic brain cancers and methylphenidate should not be administered prophylactically for this indication (84).

Data regarding treatments for patients who have already developed significant neurocognitive deficits are scarce. A randomized trial comparing a structured multidisciplinary intervention to standard care improved overall patient QOL but failed to show improvement in fatigue in patients receiving radiotherapy $(85,86)$. Psychostimulants such as methylphenidate and modafinil have been successfully used for cancer-related fatigue (87-91). A small, randomized study of methylphenidate (immediate release, $10 \mathrm{mg}$ BID) and modafinil (200 mg qAM) given for 4 weeks in patients with primary brain tumors found improvements in processing speed, executive function, and patient-reported fatigue, mood, and QOL (92). The acetylcholinesterase inhibitor donepezil was studied in a phase III randomized trial among patients $\geq 6$ months after partial or whole brain radiation, which failed to find a difference in its primary composite endpoint, but did result in improved memory, motor speed, and dexterity (93). The dose of donepezil was $5 \mathrm{mg}$ daily for 6 weeks followed by $10 \mathrm{mg}$ daily for 18 weeks. The benefit of drugs such as methylphenidate, modafinil, and donepezil appear to be greatest in patients with worse baseline functioning. These medications can be considered in patients with significant neurocognitive decline following radiation for brain metastases. The choice of a specific agent should be dependent on the side effect profile and tolerability.

\section{Optic neuropatby}

Radiation-induced optic neuropathy (RION) is one of the most feared complications of intracranial radiation due to its devastating consequences. RION is characterized by progressive partial to complete monocular or binocular vision loss with corresponding contrast enhancement and thickening of the affected anterior visual pathway on MRI with a history of radiation exposure to that anatomic distribution $(94,95)$. RION is rare below conventionally fractionated radiation doses of $50 \mathrm{~Gy}$ or less. The risk of RION is greater when SRS is used to treat brain metastases in close proximity to the optic nerves with an estimated risk of $1 \%$ for single fraction SRS doses of $>8$ Gy and $10 \%$ for $>12$ Gy (96).

Proven treatment options for RION are limited. Corticosteroids and therapeutic anticoagulation have been studied but do not appear to be effective when given alone $(97-100)$. HBOT is controversial for this indication, as some studies have reported improvement in vision with HBOT (101-103), whereas others have found no benefit $(100,104,105)$. When given, treatment should ideally be initiated within 72 hours of symptom onset (102). HBOT delivery regimens are variable but range from 14-30 daily sessions lasting 90-120 minutes each at 2.4-2.8 atmospheres. There are case reports of bevacizumab 
improving RION in conjunction with or following a failed trial of corticosteroids (106-108). Farooq et al. gave bevacizumab at $7.5 \mathrm{mg} / \mathrm{kg}$ q 3 weeks for 3 doses with dexamethasone and pentoxifylline while Dutta $e t$ al. gave bevacizumab $5 \mathrm{mg} / \mathrm{kg}$ alone initially followed by $10 \mathrm{mg} / \mathrm{kg}$ q2 weeks for up to 6 doses. Animal models have demonstrated efficacy of the ACE inhibitor ramipril in mitigating RION after SRS, but this therapy remains experimental in humans $(109,110)$.

When monocular RION occurs, the contralateral eye should be carefully observed with serial clinical exams and imaging as patients are at higher risk of developing subsequent contralateral RION. Unfortunately, there is no evidence that prophylactic treatment is effective in preventing RION, but early HBOT can be considered if imaging changes develop, even in the absence of clinical symptoms (103).

\section{Neuroendocrine dysfunction}

Historically, patients with brain metastases rarely survived long enough to develop clinically significant hypothalamicpituitary (HP) axis dysfunction following treatment of brain metastases with radiotherapy and HP dysfunction in this population is therefore not well-described in literature. HP dysfunction is related to dose to the pituitary gland and is rare with doses of $<20$ Gy but occurs frequently with doses of $>50$ Gy (111). Reported latency times range widely from 1-26 years after radiation treatment, but most cases are thought to occur between 1-5 years after radiation (112). Extrapolating from data in patients with primary brain tumors, it would be reasonable to screen patients with brain metastases surviving longer than 1 year after WBRT annually for endocrine deficiencies with hormone replacement as clinically indicated (113-115).

\section{Complications after neurosurgical resection}

The morbidity and mortality of neurosurgical interventions for brain metastases have improved considerably in the last few decades (116,117). An analysis of over 13,500 admissions for metastatic brain tumor resections across the US demonstrated that the mortality rate had decreased by $49 \%$ from 1988 to 2000 (118). The mortality risk is now estimated to be approximately $0.7-1.9 \%$ based on modern series $(119,120)$. Nevertheless, caring for the neurosurgical patient requires close observation in the immediate postoperative period. A multidisciplinary approach is favored, and care should be delivered by a team comprised of a neurosurgeon, neuro-intensivists, anesthesiologists, and specialized nursing staff (121). Timely detection of neurologic changes is crucial for early diagnosis and quick intervention of any post-surgical complications (Table 2).

\section{Neurologic deficit}

As many as $20-40 \%$ of patients with metastatic brain tumors will present with focal neurologic deficits (122). Surgery aims to remove the tumor and reverse or improve neurologic symptoms, but injury to normal brain structures is possible, which may result in permanent neurologic deficits. Numerous modalities are used to preserve neurological function when possible, including advanced neuro-imaging with diffusion tractography imaging, minimally invasive approaches, awake craniotomy for speech monitoring, and use of cortical and subcortical motor mapping during tumor resection. The overall neurologic morbidity is estimated to be $3.9-6 \%$ (120). Patients with new neurologic deficits after surgery should be rapidly assessed to identify potentially reversible causes, including ICH, hematoma, cerebral edema, and seizures. In many cases, however, the probable cause is not discovered, though most deficits improve over time (123). In one study of neurologic deficits after surgery for primary brain tumors, two-thirds of patients were able to make a complete recovery, and another $\sim 15 \%$ had a near-complete recovery with no impairment of function (124). Neurological and/ or neurocognitive rehabilitation have been associated with improved motor and cognitive function and QOL and should be tailored to each patient's specific impairments and goals (125).

\section{Intracranial bemorrhage}

Hypertension and coagulopathy are the main predisposing risk factors for ICH after neurosurgical resection, and efforts should be focused on prevention and early correction to reduce this risk. Hypertension can be precipitated by pain or may be part of the Cushing reflex. Strict blood pressure control is encouraged during surgery and postoperatively. A retrospective study of over 11,000 patients undergoing craniotomy found that patients who experienced hypertension of $\geq 160 / 90$ during surgery or in the early postoperative period were more likely to have an ICH event (126).

Patients with ICH should be managed in an intensive 
Table 2 Neurosurgical complications of brain metastasis treatment and management options

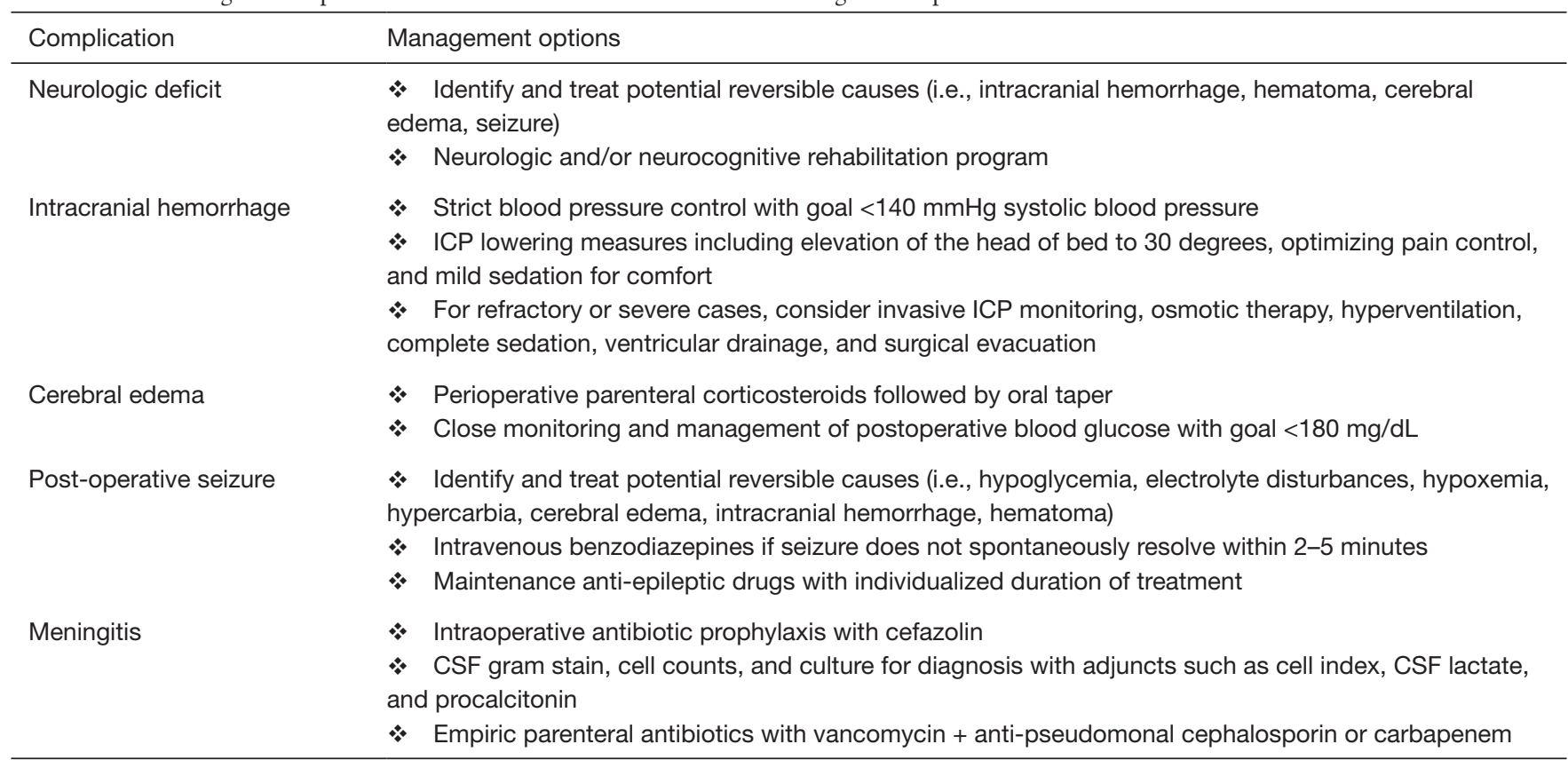

ICP, intracranial pressure; CSF, cerebrospinal fluid.

care unit with close management of blood pressure with a goal of $<140 \mathrm{mmHg}$ systolic and ICP lowering measures including elevation of the head of bed to 30 degrees, optimizing pain control, and mild sedation for comfort. More aggressive measures such as invasive ICP monitoring, osmotic therapy, hyperventilation, complete sedation, ventricular drainage, and surgical evacuation are options for refractory patients or severe cases (127).

\section{Cerebral edema}

Cerebral edema is commonly seen after craniotomy and may be exacerbated by prolonged brain retraction and hypertension. The symptoms are generally insidious and non-specific (nausea, diffuse headache). Severe cases may be associated with neurologic deficits depending on the location of the edema. Corticosteroids are usually administered at the time of surgery and then transitioned to a short oral taper to reduce the risk of cerebral edema. Typical dosing is $10 \mathrm{mg}$ IV dexamethasone followed by $4 \mathrm{mg}$ every 6 hours, but the dosing is individualized based on the patient's symptoms before and after surgery. Hyperglycemia is a common side-effect of corticosteroids and blood glucose is closely monitored and corrected postoperatively when levels are $>180 \mathrm{mg} / \mathrm{dL}(128,129)$.

\section{Post-operative seizure}

The incidence of postoperative seizure following craniotomy is approximately $5-15 \%$ (130). Precipitating medical factors may include hypoglycemia, electrolyte disturbances, hypoxemia, and/or hypercarbia. Prophylactic antiepileptic drugs (AEDs) are not indicated for patients with brain metastases as they have not shown a benefit in seizure reduction, even in the peri-operative setting $(130,131)$. Most acute seizures spontaneously resolve within two minutes, but more protracted seizures may require infusion of intravenous benzodiazepines. An urgent CT scan is recommended if a reversible surgical cause is suspected such as cerebral edema, hemorrhage, hematoma, and/or elevated ICP. In addition to treating the underlying condition, AEDs such as levetiracetam or phenytoin should be added for maintenance in the recovery period. Postoperative seizures have a low risk of progression to epilepsy overall but decisions on length of time to continue AEDs should be individualized.

\section{Meningitis}

Infections following a craniotomy can include surgical site infections and, rarely, meningitis. Postoperative meningitis is a severe disease with high morbidity and mortality rates, 
making early diagnosis and treatment crucial. The use of indwelling catheters or other CSF draining devices can increase the risk for meningitis. Antibiotic prophylaxis can be used intraoperatively and most guidelines recommend cefazolin as the antibiotic of choice for prophylaxis in craniotomies, but there is no evidence to support continuation after surgery (132).

Symptoms of postoperative meningitis compared to community-acquired meningitis are non-specific and should be suspected with fever and/or an altered level of consciousness (133). The diagnosis is made primarily through CSF gram stain, cell counts, and culture. A positive gram stain should prompt empiric treatment but with a negative gram stain, classic CSF findings of leukocytosis and neutrophilia have low specificity in the postoperative setting. As a result, other lab values may be used to guide clinical decision making. An elevated cell index of $\geq 5$ (a ratio of white blood cells to erythrocytes), high CSF lactate ( $>4 \mathrm{mmol} / \mathrm{L}$ ), and elevated procalcitonin have all been associated with bacterial meningitis (133). The treatment is empiric parenteral antibiotics with vancomycin plus either an anti-pseudomonal cephalosporin or carbapenem per the 2017 Infectious Diseases Society of America (IDSA) guidelines (134).

\section{Complications after brain metastasis directed systemic therapy}

\section{Checkpoint inbibitor immunotherapy}

Checkpoint inhibitors include antibodies against cytotoxic T lymphocyte-associated antigen 4 (CTLA-4) such as ipilimumab, programmed cell death receptor 1 (PD-1) such as nivolumab, and programmed cell death ligand 1 (PD-L1) such as atezolizumab. Combination ipilimumab and nivolumab were studied for upfront treatment of melanoma brain metastases (14). Checkpoint inhibitors are associated with a wide range of potential side effects, referred to as immune-related adverse events (irAEs), caused by enhancement of the immune system and the ubiquitous presence of immune cells throughout the body (Table 3). Well-documented irAEs include pruritic skin rash, arthralgias/myalgias, colitis, pneumonitis, hepatitis, and endocrinopathies, although many other potential irAEs exist. The incidence of any irAE is as high as $90 \%$ while the incidence of severe grade $\geq 3$ irAE ranges from 10-43\% depending on the agent, population, and study (135-137). The treatment-related death rate is as high as $2 \%(138)$.
Organ-specific practice guidelines exist for management of irAEs (138-140). Most grade $\geq 2$ toxicities should be discussed and managed carefully with appropriate organ specialists. Potential options for irAEs include continued treatment with observation, symptom management, temporary or permanent suspension of immunotherapy, topical or systemic corticosteroids, disease-modifying antirheumatic drugs, and other organ-specific interventions (140).

Immunotherapy can rarely be associated with an autoimmune meningoencephalitis typically occurring between 1-7 weeks following initiation of immunotherapy (141). Meningeal enhancement can be seen on MRI and this must be differentiated from leptomeningeal disease or infectious etiologies with CSF analysis. Autoimmune meningoencephalitis responds to high-dose corticosteroids.

Pseudoprogression of brain metastases after treatment with immunotherapy has also been reported (142). If suspected, the evaluation of pseudoprogression in patients receiving immunotherapy is similar to that of other patients (See above "Pseudoprogression" section). Corticosteroids should be administered when clinically indicated for neurologic symptoms with a slow taper over at least 4-6 weeks, as in other irAEs. A starting dose of either prednisone at $1 \mathrm{mg} / \mathrm{kg}$ or dexamethasone equivalent are acceptable options.

There is no consensus on the optimal timing of immunotherapy with radiotherapy. Overall, the toxicity profile of combination therapy is not significantly worse than with immunotherapy alone (143), although some have reported higher rates of radiation necrosis (144). However, as there is no evidence that withholding immunotherapy during radiotherapy reduces side effects, we do not advocate for this approach.

In general, for mild, grade 1 irAEs, immunotherapy can continue with close clinical supervision, and corticosteroids are not necessary. Grade $\geq 2$ events require temporary suspension of immunotherapy with optional administration of low-dose corticosteroids if the irAEs do not promptly improve with discontinuation of immunotherapy. Immunotherapy may be resumed after improvement of the irAE to grade $0-1$ and tapering of corticosteroids to a prednisone equivalent of $<10 \mathrm{mg} / \mathrm{day}$ (139). Grade $\geq 3$ events should be managed with high-dose systemic corticosteroids, possibly as an inpatient, and resumption of immunotherapy should be considered on a case-by-case basis depending on the perceived risk/benefit ratio. Immunotherapy should be permanently discontinued following a grade 4 event.

When initiated, low-dose prednisone is dosed at 
Table 3 Systemic therapy complications of brain metastasis treatment and management options

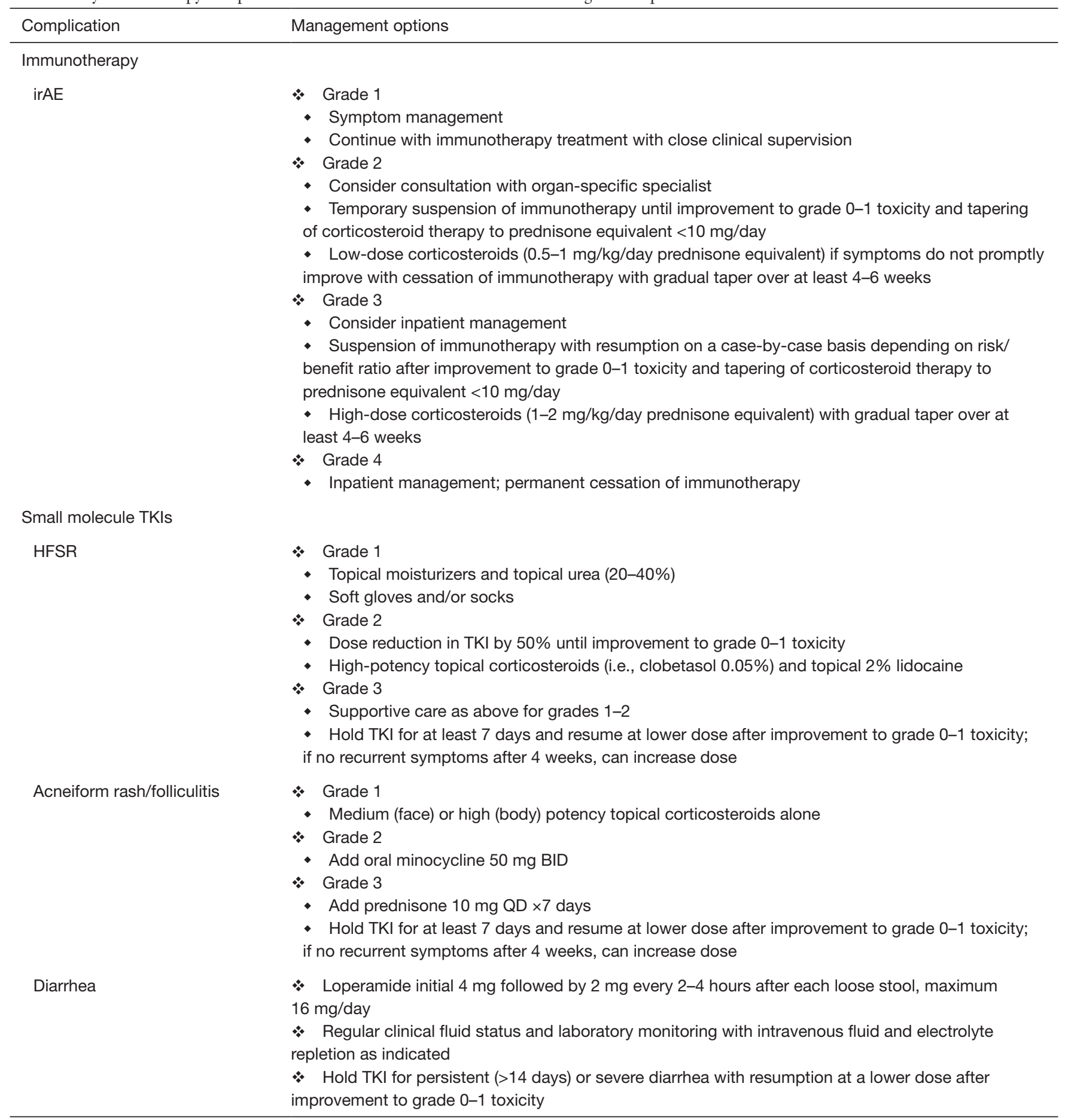

irAE, immune-related adverse event; TKI, tyrosine kinase inhibitor; HFSR, hand-foot skin reaction; BID, twice daily; QD, once daily. 
0.5 to $1 \mathrm{mg} / \mathrm{kg} /$ day and high-dose prednisone at 1 to $2 \mathrm{mg} / \mathrm{kg} /$ day (139). Corticosteroids should be tapered slowly over at least 4-6 weeks. Although data is still evolving, there does not appear to be a significant negative impact on immunotherapy overall response rate if corticosteroids are initiated after the appearance of irAEs (145).

\section{Small molecule tyrosine kinase inbibitors (TKIs)}

Small molecule TKIs are orally bioavailable targeted therapy agents, a number of which have been studied for brain metastasis treatment in recent years including erlotinib, gefitinib, neratinib, and tucatinib (2,15-17). TKIs are associated with a unique dermatologic side effect profile.

Multi-targeted TKIs (i.e., sorafenib, sunitinib) cause a characteristic hand-foot skin reaction (HFSR) in up to $60 \%$ of treated patients (146-149). HFSR is characterized by hyperkeratotic, calloused lesions on the palms and soles with surrounding erythema within the first 2-4 weeks of TKI initiation. For grade 1 HFSR, TKI dose can be maintained with supportive care including topical moisturizers, topical urea $(20-40 \%)$, and soft gloves or socks $(148,150)$. For grade 2 HFSR, TKI dose should be reduced by $50 \%$ until improvement to grade $0-1$ and high-potency topical corticosteroids (i.e., clobetasol $0.05 \%$ ) with topical $2 \%$ lidocaine given. For grade 3 HFSR, treatment should be interrupted for at least 7 days and supportive treatment as in grades 1-2 HFSR given. After improvement to grade 0-1, the TKI may be resumed at a lower dose and after at least 4 weeks without recurrence or worsening of HFSR, the dose may be increased.

The most common side effects caused by EGFR selective TKIs (i.e., erlotinib, gefitinib) include a dosedependent acneiform rash/folliculitis and diarrhea $(151,152)$. Acneiform rash is managed according to severity and for grade 1 can be treated with medium-high potency topical steroids alone. Oral minocycline $50 \mathrm{mg}$ BID should be added for grade 2 toxicity and a short course of oral prednisone $10 \mathrm{mg}$ daily $\times 7$ days should be added for grade 3 toxicity (151). Co-management with dermatology should be considered for grade 2 -3 rash. Severe rash unresponsive to medical treatment should prompt interruption of TKI therapy with consideration of resumption at a reduced dose after improvement to grade $0-1$ toxicity. Severe cutaneous reactions should alert providers to the possibility of StevensJohnsons syndrome (SJS)/toxic epidermal necrolysis (TEN) as rare cases have been reported with TKIs (153).

While TKIs concurrent with WBRT may be associated with worse dermatologic toxicity (154), numerous studies have not found TKIs to be associated with worse neurologic toxicity with WBRT or SRS (155). A study in nonsmall cell lung cancer patients with $\geq 2$ brain metastases randomly assigned patients to either WBRT or WBRT with erlotinib. There was no difference in intracranial PFS or cognitive function with concurrent erlotinib compared to WBRT alone suggesting safety but no justification for adding concurrent EGFR-TKI with WBRT (156). Thus, for treatment-naïve patients with brain metastases, we prefer upfront radiotherapy followed by TKI, but for those patients already receiving TKI administration at the time of radiotherapy evaluation, interruption of TKI therapy may not be necessary. If TKI interruption is preferred, a one-week period before and after radiotherapy is sufficient.

Diarrhea should be managed with supportive care. Loperamide can be used with an initial dose of $4 \mathrm{mg}$ followed by $2 \mathrm{mg}$ every 2-4 hours after each loose stool, titrating to 1-2 bowel movements a day with a maximum daily dose of $16 \mathrm{mg}$ (157-159). In the setting of diarrhea, clinical fluid status assessment should be performed regularly with a low threshold for intravenous fluid administration. Electrolytes should be monitored and repleted as needed, and patients who are acutely ill should be managed as an inpatient. TKI therapy should be withheld for severe or persistent ( $>14$ days) diarrhea with consideration of resumption at a reduced dose after improvement to grade $0-1$.

\section{Conclusions}

The incidence of brain metastases is increasing due to more advanced imaging modalities, more frequent brain imaging, and improved cancer treatments for metastatic disease. Furthermore, numerous new and effective multimodality brain metastasis therapies have been developed over recent years that have led to both improved survival in patients with brain metastases and better preservation of neurocognitive function. As a result, however, brain metastasis therapies are associated with a greater range of potential side effects than ever before, and clinicians are tasked with the challenge of effectively managing these side effects without compromising cancer outcomes. In this review, we have summarized the major complications from intracranial radiotherapy, neurosurgical resection, and brain metastasis directed systemic therapy and corresponding evidenced-based, modern management principles to guide the practicing oncologist. 


\section{Acknowledgments}

Funding: Direct infrastructure support was provided by the MD Anderson Cancer Center Support Grant (P30CA016672).

\section{Footnote}

Provenance and Peer Review: This article was commissioned by the Guest Editors (Simon S. Lo, Balamurugan Vellayappan, Kevin Shiue and Jonathan P. S. Knisely) for the series "The Modern Approaches to the Management of Brain Metastases" published in Chinese Clinical Oncology. The article has undergone external peer review.

Reporting Checklist: The authors have completed the Narrative Review reporting checklist. Available at https:// cco.amegroups.com/article/view/10.21037/cco-21-90/rc

Conflicts of Interest: All authors have completed the ICMJE uniform disclosure form (available at https://cco.amegroups. com/article/view/10.21037/cco-21-90/coif). The series "The Modern Approaches to the Management of Brain Metastases" was commissioned by the editorial office without any funding or sponsorship. SN reports consulting fees from Seagen unrelated to the current work. The authors have no other conflicts of interest to declare.

Ethical Statement: The authors are accountable for all aspects of the work in ensuring that questions related to the accuracy or integrity of any part of the work are appropriately investigated and resolved.

Open Access Statement: This is an Open Access article distributed in accordance with the Creative Commons Attribution-NonCommercial-NoDerivs 4.0 International License (CC BY-NC-ND 4.0), which permits the noncommercial replication and distribution of the article with the strict proviso that no changes or edits are made and the original work is properly cited (including links to both the formal publication through the relevant DOI and the license). See: https://creativecommons.org/licenses/by-nc-nd/4.0/.

\section{References}

1. Ostrom QT, Wright CH, Barnholtz-Sloan JS. Brain metastases: epidemiology. Handb Clin Neurol 2018;149:27-42.
2. Murthy RK, Loi S, Okines A, et al. Tucatinib, Trastuzumab, and Capecitabine for HER2-Positive Metastatic Breast Cancer. N Engl J Med 2020;382:597-609.

3. Nayak L, Lee EQ, Wen PY. Epidemiology of brain metastases. Curr Oncol Rep 2012;14:48-54.

4. Suh JH, Kotecha R, Chao ST, et al. Current approaches to the management of brain metastases. Nat Rev Clin Oncol 2020;17:279-99.

5. Arvanitis CD, Ferraro GB, Jain RK. The blood-brain barrier and blood-tumour barrier in brain tumours and metastases. Nat Rev Cancer 2020;20:26-41.

6. Patchell RA, Tibbs PA, Walsh JW, et al. A randomized trial of surgery in the treatment of single metastases to the brain. N Engl J Med 1990;322:494-500.

7. Patchell RA, Tibbs PA, Regine WF, et al. Postoperative radiotherapy in the treatment of single metastases to the brain: a randomized trial. JAMA 1998;280:1485-9.

8. Chang EL, Wefel JS, Hess KR, et al. Neurocognition in patients with brain metastases treated with radiosurgery or radiosurgery plus whole-brain irradiation: a randomised controlled trial. Lancet Oncol 2009;10:1037-44.

9. Brown PD, Jaeckle K, Ballman KV, et al. Effect of Radiosurgery Alone vs Radiosurgery With Whole Brain Radiation Therapy on Cognitive Function in Patients With 1 to 3 Brain Metastases: A Randomized Clinical Trial. JAMA 2016;316:401-9.

10. Aoyama H, Shirato H, Tago M, et al. Stereotactic radiosurgery plus whole-brain radiation therapy vs stereotactic radiosurgery alone for treatment of brain metastases: a randomized controlled trial. JAMA 2006;295:2483-91.

11. Kocher M, Soffietti R, Abacioglu U, et al. Adjuvant wholebrain radiotherapy versus observation after radiosurgery or surgical resection of one to three cerebral metastases: results of the EORTC 22952-26001 study. J Clin Oncol 2011;29:134-41.

12. Mahajan A, Ahmed S, McAleer MF, et al. Post-operative stereotactic radiosurgery versus observation for completely resected brain metastases: a single-centre, randomised, controlled, phase 3 trial. Lancet Oncol 2017;18:1040-8.

13. Brown PD, Ballman KV, Cerhan JH, et al. Postoperative stereotactic radiosurgery compared with whole brain radiotherapy for resected metastatic brain disease (NCCTG N107C/CEC.3): a multicentre, randomised, controlled, phase 3 trial. Lancet Oncol 2017;18:1049-60.

14. Tawbi HA, Forsyth PA, Algazi A, et al. Combined Nivolumab and Ipilimumab in Melanoma Metastatic to the Brain. N Engl J Med 2018;379:722-30. 
15. Freedman RA, Gelman RS, Anders CK, et al. TBCRC 022: A Phase II Trial of Neratinib and Capecitabine for Patients With Human Epidermal Growth Factor Receptor 2-Positive Breast Cancer and Brain Metastases. J Clin Oncol 2019;37:1081-9.

16. Iuchi T, Shingyoji M, Sakaida T, et al. Phase II trial of gefitinib alone without radiation therapy for Japanese patients with brain metastases from EGFR-mutant lung adenocarcinoma. Lung Cancer 2013;82:282-7.

17. Park SJ, Kim HT, Lee DH, et al. Efficacy of epidermal growth factor receptor tyrosine kinase inhibitors for brain metastasis in non-small cell lung cancer patients harboring either exon 19 or 21 mutation. Lung Cancer 2012;77:556-60.

18. Diao K, Bian SX, Routman DM, et al. Stereotactic radiosurgery and ipilimumab for patients with melanoma brain metastases: clinical outcomes and toxicity. J Neurooncol 2018;139:421-9.

19. Diao K, Bian SX, Routman DM, et al. Combination ipilimumab and radiosurgery for brain metastases: tumor, edema, and adverse radiation effects. J Neurosurg 2018;129:1397-406.

20. Smart D. Radiation Toxicity in the Central Nervous System: Mechanisms and Strategies for Injury Reduction. Semin Radiat Oncol 2017;27:332-9.

21. Cox JD, Stetz J, Pajak TF. Toxicity criteria of the Radiation Therapy Oncology Group (RTOG) and the European Organization for Research and Treatment of Cancer (EORTC) Int J Radiat Oncol Biol Phys 1995;31:1341-6.

22. Greene-Schloesser D, Robbins ME, Peiffer AM, et al. Radiation-induced brain injury: A review. Front Oncol 2012;2:73.

23. Tofilon PJ, Fike JR. The radioresponse of the central nervous system: a dynamic process. Radiat Res 2000;153:357-70.

24. Kondziolka D, Niranjan A, Flickinger JC, et al. Radiosurgery with or without whole-brain radiotherapy for brain metastases: the patients' perspective regarding complications. Am J Clin Oncol 2005;28:173-9.

25. Pulenzas N, Khan L, Tsao M, et al. Fatigue scores in patients with brain metastases receiving whole brain radiotherapy. Support Care Cancer 2014;22:1757-63.

26. Mulvenna P, Nankivell M, Barton R, et al. Dexamethasone and supportive care with or without whole brain radiotherapy in treating patients with nonsmall cell lung cancer with brain metastases unsuitable for resection or stereotactic radiotherapy (QUARTZ): results from a phase 3 , non-inferiority, randomised trial.
Lancet 2016;388:2004-14.

27. Bower JE, Bak K, Berger A, et al. Screening, assessment, and management of fatigue in adult survivors of cancer: an American Society of Clinical oncology clinical practice guideline adaptation. J Clin Oncol 2014;32:1840-50.

28. Segal R, Evans W, Johnson D, et al. Structured exercise improves physical functioning in women with stages I and II breast cancer: results of a randomized controlled trial. J Clin Oncol 2001;19:657-65.

29. Segal RJ, Reid RD, Courneya KS, et al. Resistance exercise in men receiving androgen deprivation therapy for prostate cancer. J Clin Oncol 2003;21:1653-9.

30. Segal RJ, Reid RD, Courneya KS, et al. Randomized controlled trial of resistance or aerobic exercise in men receiving radiation therapy for prostate cancer. J Clin Oncol 2009;27:344-51.

31. Windsor PM, Nicol KF, Potter J. A randomized, controlled trial of aerobic exercise for treatment-related fatigue in men receiving radical external beam radiotherapy for localized prostate carcinoma. Cancer 2004;101:550-7.

32. Freites-Martinez A, Shapiro J, van den Hurk C, et al. Hair disorders in cancer survivors. J Am Acad Dermatol 2019;80:1199-213.

33. Scoccianti S, Simontacchi G, Greto D, et al. Dosimetric Predictors of Acute and Chronic Alopecia in Primary Brain Cancer Patients Treated With Volumetric Modulated Arc Therapy. Front Oncol 2020;10:467.

34. Chidambaram S, Macaluso D, Pannullo SC. Alopecia following cranial stereotactic radiosurgery: A comprehensive review of the literature. J Clin Neurosci 2020;80:203-6.

35. Phillips GS, Freret ME, Friedman DN, et al. Assessment and Treatment Outcomes of Persistent Radiation-Induced Alopecia in Patients With Cancer. JAMA Dermatol 2020;156:963-72.

36. Witek M, Vahknenko Y, Siglin J, et al. Dose Reduction to the Scalp with Hippocampal Sparing Is Achievable with Intensity Modulated Radiotherapy. Int J Med Phys Clin Eng Radiat Oncol 2014;3:176-82.

37. Mahadevan A, Sampson C, LaRosa S, et al. Dosimetric analysis of the alopecia preventing effect of hippocampus sparing whole brain radiation therapy. Radiat Oncol 2015;10:245.

38. Mendelsohn FA, Divino CM, Reis ED, et al. Wound care after radiation therapy. Adv Skin Wound Care 2002;15:216-24.

39. Vecht CJ, Hovestadt A, Verbiest HB, et al. Dose-effect relationship of dexamethasone on Karnofsky performance 
in metastatic brain tumors: a randomized study of doses of 4, 8, and $16 \mathrm{mg}$ per day. Neurology 1994;44:675-80.

40. Ryken TC, McDermott M, Robinson PD, et al. The role of steroids in the management of brain metastases: a systematic review and evidence-based clinical practice guideline. J Neurooncol 2010;96:103-14.

41. Schroeder T, Bittrich P, Noebel C, et al. Efficiency of Dexamethasone for Treatment of Vasogenic Edema in Brain Metastasis Patients: A Radiographic Approach. Front Oncol 2019;9:695.

42. Hatam A, Yu ZY, Bergström M, et al. Effect of dexamethasone treatment on peritumoral brain edema: evaluation by computed tomography. J Comput Assist Tomogr 1982;6:586-92.

43. Kural C, Atac GK, Tehli O, et al. The evaluation of the effects of steroid treatment on the tumor and peritumoral edema by DWI and MR spectroscopy in brain tumors. Neurol Neurochir Pol 2018;52:495-504.

44. Basch E, Hesketh PJ, Kris MG, et al. Antiemetics: american society of clinical oncology clinical practice guideline update. J Oncol Pract 2011;7:395-8.

45. Ruhlmann CH, Jahn F, Jordan K, et al. 2016 updated MASCC/ESMO consensus recommendations: prevention of radiotherapy-induced nausea and vomiting. Support Care Cancer 2017;25:309-16.

46. Hesketh PJ, Kris MG, Basch E, et al. Antiemetics: ASCO Guideline Update. J Clin Oncol 2020;38:2782-97.

47. Parvez K, Parvez A, Zadeh G. The diagnosis and treatment of pseudoprogression, radiation necrosis and brain tumor recurrence. Int J Mol Sci 2014;15:11832-46.

48. Wiggenraad R, Bos P, Verbeek-de Kanter A, et al. Pseudo-progression after stereotactic radiotherapy of brain metastases: lesion analysis using MRI cine-loops. J Neurooncol 2014;119:437-43.

49. Thust SC, van den Bent MJ, Smits M. Pseudoprogression of brain tumors. J Magn Reson Imaging 2018;48:571-89.

50. Umemura Y, Wang D, Peck KK, et al. DCE-MRI perfusion predicts pseudoprogression in metastatic melanoma treated with immunotherapy. J Neurooncol 2020;146:339-46.

51. Morabito R, Alafaci C, Pergolizzi S, et al. DCE and DSC perfusion MRI diagnostic accuracy in the follow-up of primary and metastatic intra-axial brain tumors treated by radiosurgery with cyberknife. Radiat Oncol 2019;14:65.

52. Digernes I, Grøvik E, Nilsen LB, et al. Brain metastases with poor vascular function are susceptible to pseudoprogression after stereotactic radiation surgery. Adv Radiat Oncol 2018;3:559-67.
53. Chambless LB, Angel FB, Abel TW, et al. Delayed cerebral radiation necrosis following treatment for a plasmacytoma of the skull. Surg Neurol Int 2010;1:65.

54. Brandsma D, Stalpers L, Taal W, et al. Clinical features, mechanisms, and management of pseudoprogression in malignant gliomas. Lancet Oncol 2008;9:453-61.

55. Sayan M, Şahin B, Mustafayev TZ, et al. Risk of symptomatic radiation necrosis in patients treated with stereotactic radiosurgery for brain metastases. Neurocirugia (Astur : Engl Ed) 2021;32:261-7.

56. Kim JM, Miller JA, Kotecha R, et al. The risk of radiation necrosis following stereotactic radiosurgery with concurrent systemic therapies. J Neurooncol 2017;133:357-68.

57. Sneed PK, Mendez J, Vemer-van den Hoek JG, et al. Adverse radiation effect after stereotactic radiosurgery for brain metastases: incidence, time course, and risk factors. J Neurosurg 2015;123:373-86.

58. Minniti G, Clarke E, Lanzetta G, et al. Stereotactic radiosurgery for brain metastases: analysis of outcome and risk of brain radionecrosis. Radiat Oncol 2011;6:48.

59. Hu LS, Baxter LC, Smith KA, et al. Relative cerebral blood volume values to differentiate high-grade glioma recurrence from posttreatment radiation effect: direct correlation between image-guided tissue histopathology and localized dynamic susceptibility-weighted contrastenhanced perfusion MR imaging measurements. AJNR Am J Neuroradiol 2009;30:552-8.

60. Sugahara T, Korogi Y, Tomiguchi S, et al. Posttherapeutic intraaxial brain tumor: the value of perfusion-sensitive contrast-enhanced MR imaging for differentiating tumor recurrence from nonneoplastic contrast-enhancing tissue. AJNR Am J Neuroradiol 2000;21:901-9.

61. Mitsuya K, Nakasu Y, Horiguchi S, et al. Perfusion weighted magnetic resonance imaging to distinguish the recurrence of metastatic brain tumors from radiation necrosis after stereotactic radiosurgery. J Neurooncol 2010;99:81-8.

62. Asao C, Korogi Y, Kitajima M, et al. Diffusionweighted imaging of radiation-induced brain injury for differentiation from tumor recurrence. AJNR Am J Neuroradiol 2005;26:1455-60.

63. Nael K, Bauer AH, Hormigo A, et al. Multiparametric MRI for Differentiation of Radiation Necrosis From Recurrent Tumor in Patients With Treated Glioblastoma. AJR Am J Roentgenol 2018;210:18-23.

64. Anbarloui MR, Ghodsi SM, Khoshnevisan A, et al. Accuracy of magnetic resonance spectroscopy in 
distinction between radiation necrosis and recurrence of brain tumors. Iran J Neurol 2015;14:29-34.

65. Vellayappan B, Tan CL, Yong C, et al. Diagnosis and Management of Radiation Necrosis in Patients With Brain Metastases. Front Oncol 2018;8:395.

66. Levin VA, Bidaut L, Hou P, et al. Randomized doubleblind placebo-controlled trial of bevacizumab therapy for radiation necrosis of the central nervous system. Int J Radiat Oncol Biol Phys 2011;79:1487-95.

67. Xu Y, Rong X, Hu W, et al. Bevacizumab Monotherapy Reduces Radiation-induced Brain Necrosis in Nasopharyngeal Carcinoma Patients: A Randomized Controlled Trial. Int J Radiat Oncol Biol Phys 2018;101:1087-95.

68. McPherson CM, Warnick RE. Results of contemporary surgical management of radiation necrosis using frameless stereotaxis and intraoperative magnetic resonance imaging. J Neurooncol 2004;68:41-7.

69. Hong CS, Deng D, Vera A, et al. Laser-interstitial thermal therapy compared to craniotomy for treatment of radiation necrosis or recurrent tumor in brain metastases failing radiosurgery. J Neurooncol 2019;142:309-17.

70. Chuba PJ, Aronin P, Bhambhani K, et al. Hyperbaric oxygen therapy for radiation-induced brain injury in children. Cancer 1997;80:2005-12.

71. Kohshi K, Imada H, Nomoto S, et al. Successful treatment of radiation-induced brain necrosis by hyperbaric oxygen therapy. J Neurol Sci 2003;209:115-7.

72. Leber KA, Eder HG, Kovac H, et al. Treatment of cerebral radionecrosis by hyperbaric oxygen therapy. Stereotact Funct Neurosurg 1998;70 Suppl 1:229-36.

73. Glantz MJ, Burger PC, Friedman AH, et al. Treatment of radiation-induced nervous system injury with heparin and warfarin. Neurology 1994;44:2020-7.

74. Rizzoli HV, Pagnanelli DM. Treatment of delayed radiation necrosis of the brain. A clinical observation. J Neurosurg 1984;60:589-94.

75. Williamson R, Kondziolka D, Kanaan H, et al. Adverse radiation effects after radiosurgery may benefit from oral vitamin $\mathrm{E}$ and pentoxifylline therapy: a pilot study. Stereotact Funct Neurosurg 2008;86:359-66.

76. Meyers CA, Smith JA, Bezjak A, et al. Neurocognitive function and progression in patients with brain metastases treated with whole-brain radiation and motexafin gadolinium: results of a randomized phase III trial. J Clin Oncol 2004;22:157-65.

77. DeAngelis LM, Mandell LR, Thaler HT, et al. The role of postoperative radiotherapy after resection of single brain metastases. Neurosurgery 1989;24:798-805.

78. Yamamoto M, Serizawa T, Shuto T, et al. Stereotactic radiosurgery for patients with multiple brain metastases (JLGK0901): a multi-institutional prospective observational study. Lancet Oncol 2014;15:387-95.

79. Li J, Ludmir EB, Wang Y, et al. Stereotactic Radiosurgery versus Whole-brain Radiation Therapy for Patients with 4-15 Brain Metastases: A Phase III Randomized Controlled Trial. Int J Radiat Oncol Biol Phys 2020;108:S21-2.

80. Brown PD, Gondi V, Pugh S, et al. Hippocampal Avoidance During Whole-Brain Radiotherapy Plus Memantine for Patients With Brain Metastases: Phase III Trial NRG Oncology CC001. J Clin Oncol 2020;38:1019-29.

81. Rodríguez de Dios N, Couñago F, Murcia-Mejía M, et al. Randomized Phase III Trial of Prophylactic Cranial Irradiation With or Without Hippocampal Avoidance for Small-Cell Lung Cancer (PREMER): A GICORGOECP-SEOR Study. J Clin Oncol 2021;39:3118-27.

82. Belderbos JSA, De Ruysscher DKM, De Jaeger K, et al. Phase 3 Randomized Trial of Prophylactic Cranial Irradiation With or Without Hippocampus Avoidance in SCLC (NCT01780675). J Thorac Oncol 2021;16:840-9.

83. Brown PD, Pugh S, Laack NN, et al. Memantine for the prevention of cognitive dysfunction in patients receiving whole-brain radiotherapy: a randomized, double-blind, placebo-controlled trial. Neuro Oncol 2013;15:1429-37.

84. Butler JM Jr, Case LD, Atkins J, et al. A phase III, doubleblind, placebo-controlled prospective randomized clinical trial of d-threo-methylphenidate $\mathrm{HCl}$ in brain tumor patients receiving radiation therapy. Int $\mathrm{J}$ Radiat Oncol Biol Phys 2007;69:1496-501.

85. Brown P, Clark MM, Atherton P, et al. Will improvement in quality of life (QOL) impact fatigue in patients receiving radiation therapy for advanced cancer? Am J Clin Oncol 2006;29:52-8.

86. Rummans TA, Clark MM, Sloan JA, et al. Impacting quality of life for patients with advanced cancer with a structured multidisciplinary intervention: a randomized controlled trial. J Clin Oncol 2006;24:635-42.

87. Lower EE, Fleishman S, Cooper A, et al. Efficacy of dexmethylphenidate for the treatment of fatigue after cancer chemotherapy: a randomized clinical trial. J Pain Symptom Manage 2009;38:650-62.

88. Kerr CW, Drake J, Milch RA, et al. Effects of methylphenidate on fatigue and depression: a randomized, double-blind, placebo-controlled trial. J Pain Symptom Manage 2012;43:68-77. 
89. Spathis A, Dhillan R, Booden D, et al. Modafinil for the treatment of fatigue in lung cancer: a pilot study. Palliat Med 2009;23:325-31.

90. Blackhall L, Petroni G, Shu J, et al. A pilot study evaluating the safety and efficacy of modafinal for cancerrelated fatigue. J Palliat Med 2009;12:433-9.

91. Jean-Pierre P, Morrow GR, Roscoe JA, et al. A phase 3 randomized, placebo-controlled, double-blind, clinical trial of the effect of modafinil on cancer-related fatigue among 631 patients receiving chemotherapy: a University of Rochester Cancer Center Community Clinical Oncology Program Research base study. Cancer 2010;116:3513-20.

92. Gehring K, Patwardhan SY, Collins R, et al. A randomized trial on the efficacy of methylphenidate and modafinil for improving cognitive functioning and symptoms in patients with a primary brain tumor. J Neurooncol 2012;107:165-74.

93. Rapp SR, Case LD, Peiffer A, et al. Donepezil for Irradiated Brain Tumor Survivors: A Phase III Randomized PlaceboControlled Clinical Trial. J Clin Oncol 2015;33:1653-9.

94. Danesh-Meyer HV. Radiation-induced optic neuropathy. J Clin Neurosci 2008;15:95-100.

95. Lessell S. Friendly fire: neurogenic visual loss from radiation therapy. J Neuroophthalmol 2004;24:243-50.

96. Leavitt JA, Stafford SL, Link MJ, et al. Long-term evaluation of radiation-induced optic neuropathy after single-fraction stereotactic radiosurgery. Int J Radiat Oncol Biol Phys 2013;87:524-7.

97. Barbosa AP, Carvalho D, Marques L, et al. Inefficiency of the anticoagulant therapy in the regression of the radiation-induced optic neuropathy in Cushing's disease. J Endocrinol Invest 1999;22:301-5.

98. Landau K, Killer HE. Radiation damage. Neurology 1996;46:889.

99. Parsons JT, Bova FJ, Fitzgerald CR, et al. Radiation optic neuropathy after megavoltage external-beam irradiation: analysis of time-dose factors. Int J Radiat Oncol Biol Phys 1994;30:755-63.

100. Roden D, Bosley TM, Fowble B, et al. Delayed radiation injury to the retrobulbar optic nerves and chiasm. Clinical syndrome and treatment with hyperbaric oxygen and corticosteroids. Ophthalmology 1990;97:346-51.

101. Borruat FX, Schatz NJ, Glaser JS, et al. Visual recovery from radiation-induced optic neuropathy. The role of hyperbaric oxygen therapy. J Clin Neuroophthalmol 1993;13:98-101

102. Guy J, Schatz NJ. Hyperbaric oxygen in the treatment of radiation-induced optic neuropathy. Ophthalmology 1986;93:1083-8.
103. Malik A, Golnik K. Hyperbaric oxygen therapy in the treatment of radiation optic neuropathy. $\mathrm{J}$ Neuroophthalmol 2012;32:128-31.

104.Liu JL. Clinical analysis of radiation optic neuropathy. Zhonghua Yan Ke Za Zhi 1992;28:86-8.

105. Miller NR. Radiation-induced optic neuropathy: still no treatment. Clin Exp Ophthalmol 2004;32:233-5.

106. Farooq O, Lincoff NS, Saikali N, et al. Novel treatment for radiation optic neuropathy with intravenous bevacizumab. J Neuroophthalmol 2012;32:321-4.

107. Finger PT. Anti-VEGF bevacizumab (Avastin) for radiation optic neuropathy. Am J Ophthalmol 2007;143:335-8.

108. Dutta P, Dhandapani S, Kumar N, et al. Bevacizumab for Radiation Induced Optic Neuritis Among Aggressive Residual/Recurrent Suprasellar Tumors: More Than a Mere Antineoplastic Effect. World Neurosurg 2017;107:1044.e5-1044.e10.

109. Ryu S, Kolozsvary A, Jenrow KA, et al. Mitigation of radiation-induced optic neuropathy in rats by ACE inhibitor ramipril: importance of ramipril dose and treatment time. J Neurooncol 2007;82:119-24.

110. Kim JH, Brown SL, Kolozsvary A, et al. Modification of radiation injury by ramipril, inhibitor of angiotensinconverting enzyme, on optic neuropathy in the rat. Radiat Res 2004;161:137-42.

111.Pai HH, Thornton A, Katznelson L, et al. Hypothalamic/ pituitary function following high-dose conformal radiotherapy to the base of skull: demonstration of a doseeffect relationship using dose-volume histogram analysis. Int J Radiat Oncol Biol Phys 2001;49:1079-92.

112. Mehta P, Fahlbusch FB, Rades D, et al. Are hypothalamicpituitary (HP) axis deficiencies after whole brain radiotherapy (WBRT) of relevance for adult cancer patients? - a systematic review of the literature. BMC Cancer 2019;19:1213.

113. Constine LS, Woolf PD, Cann D, et al. Hypothalamicpituitary dysfunction after radiation for brain tumors. $\mathrm{N}$ Engl J Med 1993;328:87-94.

114. Taphoorn MJ, Heimans JJ, van der Veen EA, et al. Endocrine functions in long-term survivors of low-grade supratentorial glioma treated with radiation therapy. J Neurooncol 1995;25:97-102.

115. Arlt W, Hove U, Müller B, et al. Frequent and frequently overlooked: treatment-induced endocrine dysfunction in adult long-term survivors of primary brain tumors. Neurology 1997;49:498-506.

116.Lassen B, Helseth E, Rønning P, et al. Surgical mortality at 30 days and complications leading to recraniotomy in 
2630 consecutive craniotomies for intracranial tumors.

Neurosurgery 2011;68:1259-68; discussion 1268-9.

117. Sawaya R, Hammoud M, Schoppa D, et al. Neurosurgical outcomes in a modern series of 400 craniotomies for treatment of parenchymal tumors. Neurosurgery 1998;42:1044-55; discussion 1055-6.

118. Barker FG 2nd. Craniotomy for the resection of metastatic brain tumors in the U.S., 1988-2000: decreasing mortality and the effect of provider caseload. Cancer 2004;100:999-1007.

119. Sankey EW, Tsvankin V, Grabowski MM, et al. Operative and peri-operative considerations in the management of brain metastasis. Cancer Med 2019;8:6809-31.

120. Mut M. Surgical treatment of brain metastasis: a review. Clin Neurol Neurosurg 2012;114:1-8.

121. Mirski MA, Chang CW, Cowan R. Impact of a neuroscience intensive care unit on neurosurgical patient outcomes and cost of care: evidence-based support for an intensivist-directed specialty ICU model of care. J Neurosurg Anesthesiol 2001;13:83-92.

122. Sundaresan N, Galicich JH. Surgical treatment of brain metastases. Clinical and computerized tomography evaluation of the results of treatment. Cancer 1985;55:1382-8.

123. Hatiboglu MA, Wildrick DM, Sawaya R. The role of surgical resection in patients with brain metastases. Ecancermedicalscience 2013;7:308.

124.Zetterling M, Elf K, Semnic R, et al. Time course of neurological deficits after surgery for primary brain tumours. Acta Neurochir (Wien) 2020;162:3005-18.

125.Kushner DS, Amidei C. Rehabilitation of motor dysfunction in primary brain tumor patients $\dagger$. Neurooncol Pract 2015;2:185-91.

126. Basali A, Mascha EJ, Kalfas I, et al. Relation between perioperative hypertension and intracranial hemorrhage after craniotomy. Anesthesiology 2000;93:48-54.

127. Elliott J, Smith M. The acute management of intracerebral hemorrhage: a clinical review. Anesth Analg 2010;110:1419-27.

128.Lukins MB, Manninen PH. Hyperglycemia in patients administered dexamethasone for craniotomy. Anesth Analg 2005;100:1129-33.

129. Wass CT, Lanier WL. Glucose modulation of ischemic brain injury: review and clinical recommendations. Mayo Clin Proc 1996;71:801-12.

130. Greenhalgh J, Weston J, Dundar Y, et al. Antiepileptic drugs as prophylaxis for postcraniotomy seizures. Cochrane Database Syst Rev 2020;4:CD007286.
131. Wu AS, Trinh VT, Suki D, et al. A prospective randomized trial of perioperative seizure prophylaxis in patients with intraparenchymal brain tumors. J Neurosurg 2013;118:873-83.

132.Liu W, Ni M, Zhang Y, et al. Antibiotic prophylaxis in craniotomy: a review. Neurosurg Rev 2014;37:407-14; discussion 414.

133.Hussein K, Bitterman R, Shofty B, et al. Management of post-neurosurgical meningitis: narrative review. Clin Microbiol Infect 2017;23:621-8.

134. Tunkel AR, Hasbun R, Bhimraj A, et al. 2017 Infectious Diseases Society of America's Clinical Practice Guidelines for Healthcare-Associated Ventriculitis and Meningitis. Clin Infect Dis 2017;64:e34-65.

135. Weber JS, Yang JC, Atkins MB, et al. Toxicities of Immunotherapy for the Practitioner. J Clin Oncol 2015;33:2092-9.

136. Eggermont AM, Chiarion-Sileni V, Grob JJ, et al. Prolonged Survival in Stage III Melanoma with Ipilimumab Adjuvant Therapy. N Engl J Med 2016;375:1845-55.

137. Kumar V, Chaudhary N, Garg M, et al. Current Diagnosis and Management of Immune Related Adverse Events (irAEs) Induced by Immune Checkpoint Inhibitor Therapy. Front Pharmacol 2017;8:49. Erratum in: Front Pharmacol 2017;8:311.

138. Puzanov I, Diab A, Abdallah K, et al. Managing toxicities associated with immune checkpoint inhibitors: consensus recommendations from the Society for Immunotherapy of Cancer (SITC) Toxicity Management Working Group. J Immunother Cancer 2017;5:95.

139. Brahmer JR, Lacchetti C, Schneider BJ, et al. Management of Immune-Related Adverse Events in Patients Treated With Immune Checkpoint Inhibitor Therapy: American Society of Clinical Oncology Clinical Practice Guideline. J Clin Oncol 2018;36:1714-68.

140. Champiat S, Lambotte O, Barreau E, et al. Management of immune checkpoint blockade dysimmune toxicities: a collaborative position paper. Ann Oncol 2016;27:559-74.

141. Dalakas MC. Neurological complications of immune checkpoint inhibitors: what happens when you 'take the brakes off' the immune system. Ther Adv Neurol Disord 2018;11:1756286418799864.

142. Cohen JV, Alomari AK, Vortmeyer AO, et al. Melanoma Brain Metastasis Pseudoprogression after Pembrolizumab Treatment. Cancer Immunol Res 2016;4:179-82.

143. Sha CM, Lehrer EJ, Hwang C, et al. Toxicity in combination immune checkpoint inhibitor and radiation 
therapy: A systematic review and meta-analysis. Radiother Oncol 2020;151:141-8.

144. Martin AM, Cagney DN, Catalano PJ, et al. Immunotherapy and Symptomatic Radiation Necrosis in Patients With Brain Metastases Treated With Stereotactic Radiation. JAMA Oncol 2018;4:1123-4.

145. Weber JS, Hodi FS, Wolchok JD, et al. Safety Profile of Nivolumab Monotherapy: A Pooled Analysis of Patients With Advanced Melanoma. J Clin Oncol 2017;35:785-92.

146. Hartmann JT, Haap M, Kopp HG, et al. Tyrosine kinase inhibitors - a review on pharmacology, metabolism and side effects. Curr Drug Metab 2009;10:470-81.

147. Manchen E, Robert C, Porta C. Management of tyrosine kinase inhibitor-induced hand-foot skin reaction: viewpoints from the medical oncologist, dermatologist, and oncology nurse. J Support Oncol 2011;9:13-23.

148. Lacouture ME, Wu S, Robert C, et al. Evolving strategies for the management of hand-foot skin reaction associated with the multitargeted kinase inhibitors sorafenib and sunitinib. Oncologist 2008;13:1001-11.

149. Hojjat-Farsangi M. Small-molecule inhibitors of the receptor tyrosine kinases: promising tools for targeted cancer therapies. Int J Mol Sci 2014;15:13768-801.

150.McLellan B, Kerr H. Cutaneous toxicities of the multikinase inhibitors sorafenib and sunitinib. Dermatol Ther 2011;24:396-400.

151.Kiyohara Y, Yamazaki N, Kishi A. Erlotinib-related skin toxicities: treatment strategies in patients with metastatic non-small cell lung cancer. J Am Acad Dermatol

Cite this article as: Diao K, Sosa AJ, Zada G, Nagpal S, Chang EL. Management of complications from brain metastasis treatment: a narrative review. Chin Clin Oncol 2022;11(2):11. doi: $10.21037 /$ cco-21-90
2013;69:463-72.

152.Broekman F, Giovannetti E, Peters GJ. Tyrosine kinase inhibitors: Multi-targeted or single-targeted? World J Clin Oncol 2011;2:80-93.

153. Doesch J, Debus D, Meyer C, et al. Afatinib-associated Stevens-Johnson syndrome in an EGFR-mutated lung cancer patient. Lung Cancer 2016;95:35-8.

154. Tejwani A, Wu S, Jia Y, et al. Increased risk of high-grade dermatologic toxicities with radiation plus epidermal growth factor receptor inhibitor therapy. Cancer 2009;115:1286-99.

155. Tallet AV, Dhermain F, Le Rhun E, et al. Combined irradiation and targeted therapy or immune checkpoint blockade in brain metastases: toxicities and efficacy. Ann Oncol 2017;28:2962-76.

156. Yang Z, Zhang Y, Li R, et al. Whole-brain radiotherapy with and without concurrent erlotinib in NSCLC with brain metastases: a multicenter, open-label, randomized, controlled phase III trial. Neuro Oncol 2021;23:967-78.

157. Andreyev J, Ross P, Donnellan C, et al. Guidance on the management of diarrhoea during cancer chemotherapy. Lancet Oncol 2014;15:e447-60.

158.Benson AB 3rd, Ajani JA, Catalano RB, et al. Recommended guidelines for the treatment of cancer treatment-induced diarrhea. J Clin Oncol 2004;22:2918-26.

159. Sharma R, Tobin P, Clarke SJ. Management of chemotherapy-induced nausea, vomiting, oral mucositis, and diarrhoea. Lancet Oncol 2005;6:93-102. 